\title{
Synthesis of pyrrolizidines, indolizidines and pyrroloazepines through formal aza-[3+3] and aza-[3+2] cycloadditions of enaminones with maleic anhydride and maleimides
}

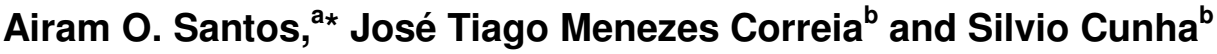

\author{
${ }^{a}$ Instituto Federal Baiano, Campus Senhor do Bonfim - 48.970-000 - Senhor do Bonfim - BA, Brasil \\ ${ }^{b}$ Universidade Federal da Bahia, Instituto de Química Campus de Ondina - 40.170-290 - Salvador - BA, Brasil \\ ${ }^{b}$ INCT de Energia e Ambiente, Universidade Federal da Bahia, Campus de Ondina - 40.170-290 - Salvador - BA \\ *airam.santos@bonfim.ifbaiano.edu.br
}

Keywords: enaminone, cycloaddition, alkaloid

\section{INTRODUCTION}

Fused bicyclic heterocycles with a bridgehead nitrogen atom is a structural scaffold present in various natural and unnatural bioactive compounds. Among these heterocycles, the pyrrolizidines, indolizidines and pyrroloazepines are important classes of alkaloids from the medicinal chemistry and chemical ecology point of views. ${ }^{1}$ We disclosure herein our results concerning the formal aza-[3+2] and formal aza-[3+3] cycloaddition reactions of cyclic enaminones, including a chiral one, with maleic anhydride and $\mathrm{N}$-aryl-maleimides, wherein pyrrolizidines, indolizidines and pyrroloazepines could be selectively obtained.

\section{RESULTS AND DISCUSSION}

Our continued interest in the chemistry of enaminones as syntons for synthesis $\mathrm{N}$ heterocycles, ${ }^{2}$ mainly in synthesis of azabicyclos from cyclic enaminones, prompted us to react enaminone $\mathbf{1 a}$ with maleic anhydride $\mathbf{2}$, in the condition described by Nagasaka et al. for ethyl ester analog of $\mathbf{1 a} .^{3}$ In this condition, we obtained the indolizidinone 3 in good yield, Scheme 1. Chiral enaminone did not afforded asymmetric induction, but seven membered one resulted in the pyrroloazepine core in excellent yield.

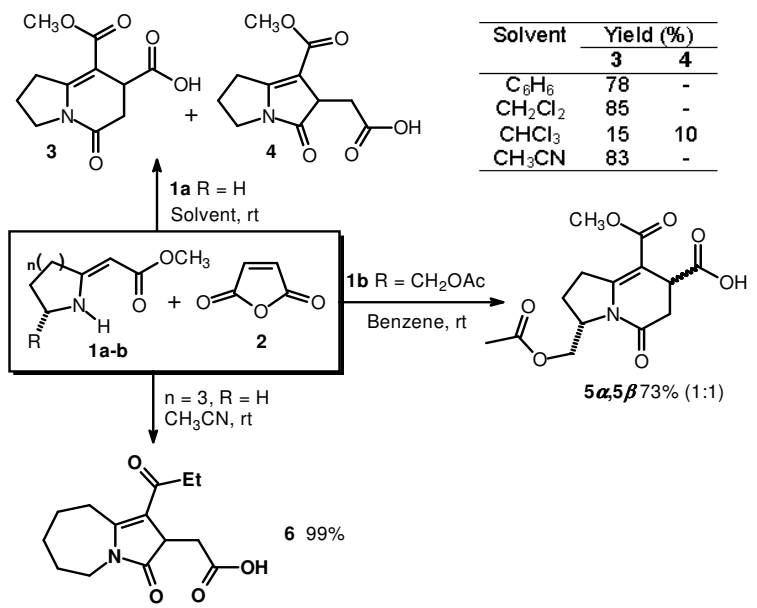

When the behavior of 1a was investigated against $\mathrm{N}$-arylmaleimides $\mathbf{7 a}$ and $\mathbf{7 b}$, only Michael adducts where obtained under reflux in acetonitrile. These results agree with those previously obtained by Nagasaka. ${ }^{3}$ However, when $p$-toluenesulfonic acid $(\mathrm{TsOH})$ was added in a catalytic amount, in the same conditions described above, a mixture of Michael adduct $\mathbf{8 a - b}$ and pirrolizidine 9a-b was obtained, as the best result obtained using $\mathbf{7 b}$. Additionaly, enaminone $\mathbf{1 c}$ reacted with $\mathbf{7 b}$, in neutral media, to give the pyrroloazepine 9 in quantitative yield, as was observed in the reaction between this enaminone and $\mathbf{2}$.

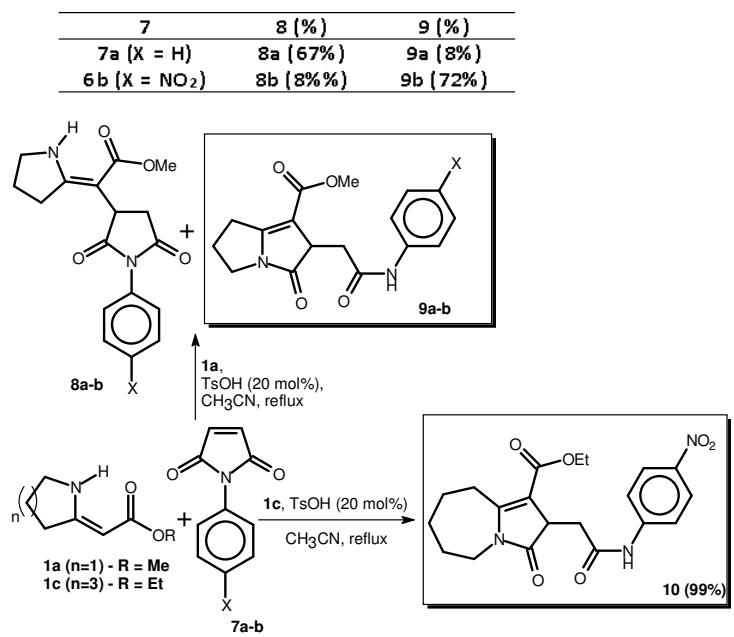

Scheme 2

\section{CONCLUSION}

This results shows a versatile route to synthesize selectively densely functionalized pyrroloazepines, pyrrolizidines and indolizidines.

\section{ACKNOWLEDGEMENTS}

CNPQ, FAPESB, CAPES

\section{REFERENCES}

${ }^{1}$ Ferraz, H. M. C. e Pereira, F. L. C. Quim. Nova 2004, 27, 89

${ }^{2}$ Das, B.; Veukateswarlu, K.; Majhi, A.; Ravinder, M. R.; Reddy, K. N.; Rao, Y.

K.; Kavikumar, K. e Sridhar, B. J. Mol. Cat. A: Chemical 2006, 246, 276-281.

${ }^{3}$ Nagaka, T.; Inoue, H.; Ichimura, M.; Hamaguchi, F. Synthesis, 1982, 10, 848 